\title{
Escolas do campo e a guetização do processo pedagógico
}

\section{Schools in the countryside and the ghettoization of the pedagogical process}

\author{
Escuela de campo y la guetización del proceso pedagógico \\ FERNANDA WANDERER (1) ${ }^{1}$ \\ DAIANE MARTINS Bocasanta (10 ${ }^{2}$ \\ ${ }^{1}$ Universidade Federal do Rio Grande do Sul, Porto Alegre, RS, Brasil. \\ ${ }^{2}$ Colégio de Aplicação, Universidade Federal do Rio Grande do Sul, Porto Alegre, RS, Brasil.
}

\begin{abstract}
RESUMO
O artigo é fruto de uma investigação desenvolvida com o propósito de examinar as enunciações sobre a escola do campo produzidas por acadêmicos de um Curso de Licenciatura em Educação do Campo. O material de pesquisa escrutinado é constituído por documentos do curso e questionários aplicados junto aos estudantes. Os aportes teóricos advêm do pensamento de Michel Foucault e Zygmunt Bauman. A análise mostrou que os discentes estão capturados pelo enunciado que diz: "a escola do campo deve trabalhar com a forma de vida do campo". Sobre a recorrência desse enunciado é possível dizer que: a) a valorização exacerbada da cultura do campo atende a uma urgência: manter na zona rural a população que nela reside, evitando seu deslocamento para as periferias das cidades; e b) reforça a guetização do processo pedagógico presente nas escolas do campo.
\end{abstract}

Palavras-chave: Escolas do campo. Licenciatura em Educação do Campo. Michel Foucault. Zygmunt Bauman.

\begin{abstract}
The article is the result of an investigation developed for the purpose of examining field school statements produced by academics of a Degree in Rural Education. The research material scrutinized consists of course documents and questionnaires applied to students. The theoretical framework for the study consists in the thinking of Michel Foucault and Zygmunt Bauman. The analysis showed that the students are captured by the statement that "the school of the field must work with the form of life of the field". On the recurrence of this statement it is possible to say that: a) the exaggerated valorization of the culture of the field attends an urgency, that is, to maintain in the rural area the population that lives in it, avoiding its displacement to the peripheries of the cities; b) reinforces the ghettoization of the pedagogical process present in the rural schools.
\end{abstract}

Keywords: countryside schools. Degree in Rural Education. Michel Foucault. Zygmunt Bauman.

\section{RESUMEN}

El artículo es fruto de una investigación desarrollada con el propósito de examinar enunciaciones sobre la escuela de campo producidas por académicos de una Carrera de Licenciatura en Educación Rural. El material de investigación examinado está constituido por documentos del Curso y cuestionarios aplicados junto a los académicos. Los aportes teóricos provienen del pensamiento de Michel Foucault y Zygmunt Bauman. El análisis mostró que los discursos están capturados por el enunciado que dice: "la escuela de campo debe trabajar con la forma de vida de campo". Sobre la recurrencia de este enunciado es posible decir que: a) la valorización exacerbada de la cultura de campo atiende a una urgencia, o sea, mantener en el medio rural a la población que allí vive, evitando su desplazamiento hacia las periferias de las ciudades; b) refuerza la guetización del proceso pedagógico presente en las escuelas de campo.

Palabras clave: Escuela de campo. Carrera de Licenciatura en Educación Rural. Michel Foucault. Zygmunt Bauman. 


\section{INTRODUÇÃo}

$\mathrm{O}$ artigo apresenta resultados de uma investigação desenvolvida com o propósito de examinar as enunciações sobre a escola do campo ${ }^{1}$ produzidas por estudantes de um Curso de Licenciatura em Educação do Campo do Rio Grande do Sul. Para essa reflexão foram examinados documentos do referido curso e questionários aplicados em todas as turmas de acadêmicos. Os aportes teóricos utilizados na investigação advêm do pensamento de Michel Foucault e Zygmunt Bauman.

A educação do campo, no Brasil, enfrenta grandes e complexos desafios que se efetivam na falta de escolas e de professores com formação específica, nos escassos materiais pedagógicos direcionados às culturas do campo, em problemas de acesso e permanência da população rural nas instituições de ensino, entre outros (HAGE, 2011; ARROYO, 2007). Mesmo assim, ao longo das últimas décadas, pode-se observar que essa área da Educação tem sido mais discutida, investigada e debatida. Essas ações emergem, basicamente, com a luta de militantes e pesquisadores vinculados a movimentos sociais, como o Movimento Sem Terra, que chamaram a atenção para a situação de abandono e/ou inferioridade que as formas de vida do campo vinham assumindo no currículo escolar e na sociedade (ARROYO, 2007; CALDART, 2000, 2002, 2003; KNIJNIK, 2006).

Assim, no cenário brasileiro contemporâneo pode-se visualizar a inclusão da educação do campo em documentos oficiais do Ministério da Educação, como nas Diretrizes Curriculares Nacionais, e em programas endereçados à escolarização básica, como o Programa Escola Ativa e o seu sucessor, Escola da Terra. Recentemente, a educação do campo passa a ser foco também de políticas públicas cuja abrangência envolve não apenas a Educação Básica, mas também o Ensino Superior, como o Programa Nacional de Educação do Campo (Pronacampo). Essa política tem como propósito a ampliação e a qualificação da oferta de educação básica e superior às populações localizadas em zonas rurais. O Programa está organizado em quatro eixos: Gestão e Práticas Pedagógicas; Formação Inicial e Continuada de Professores; Educação de Jovens e Adultos e Educação Profissional; Infraestrutura Física e Tecnológica (BRASIL, 2013b).

Decorre da organização dos eixos e do objetivo geral do Pronacampo a realização de um conjunto de

\footnotetext{
${ }^{1}$ Ao mencionar, neste artigo, "educação do campo" ou "escola do campo", seguimos as Diretrizes Curriculares Nacionais (BRASIL, 2013, p.443) que compreendem como população do campo: "os agricultores familiares, os extrativistas, os pescadores artesanais, os ribeirinhos, os assentados e acampados da reforma agrária, os trabalhadores assalariados rurais, os quilombolas, os caiçaras, os povos da floresta, os caboclos e outros que produzam suas condições materiais de existência a partir do trabalho no meio rural".
}

ações que atuam sobre as formas de vida do campo. Ao examinarmos detalhadamente suas medidas, percebemos os propósitos de atingir essa esfera da população por meio de ações como: distribuição de livros didáticos e obras que contemplem as especificidades do campo e comunidades quilombolas, promoção da educação integral nas escolas rurais, criação de cursos de formação inicial e continuada para educadores do campo, expansão de cursos de qualificação profissional específicos para o campo, bolsa-formação para estudantes e trabalhadores rurais e a disponibilização de uma série de recursos financeiros para compra de móveis e equipamentos (BRASIL, 2013b).

Apoiando-nos nas teorizações foucaultianas sobre as práticas de governamento e em estudos recentes que se serviram desse referencial para examinar políticas públicas para a educação do campo, como os desenvolvidos por Knijnik e Wanderer (2013), Wanderer e Knijnik (2014) e Wanderer (2017), compreendemos o Pronacampo como um conjunto de estratégias que fazem parte de um dispositivo de governamento da população do campo. Nosso trabalho segue, especificamente, o apontando por Knijnik e Wanderer (2013) quando examinaram o Programa Escola Ativa (PEA), endereçado às escolas multisseriadas do campo no período de 1997 até, aproximadamente, 2014. Analisando materiais disponibilizados pelo PEA aos alunos e professores, bem como questionários aplicados a educadores que atuavam no Programa, as autoras mostraram que o discurso do PEA operava sobre professores, alunos, gestores das escolas multisseriadas do campo e, no limite, sobre a população camponesa no governo de suas condutas. Ao regular as condutas dos sujeitos, o PEA funcionaria como parte de um dispositivo de governamento da população que institui uma visão despolitizada e romântica do campo e posiciona a forma de vida camponesa em um patamar inferior ao da forma de vida urbana (KNIJNIK; WANDERER, 2013).

Inspiradas naquela pesquisa, consideramos o Pronacampo como uma política pública endereçada à população do campo que também regula e conduz condutas dos sujeitos capturados por ela. Nosso empreendimento analítico esteve focado em identificar, descrever e problematizar enunciações - entendidas como centrais na operação da razão governamental estabelecida em uma determinada época e para certas sociedades (MARÍN-DIAZ, 2012) - engendradas em uma das instâncias do Pronacampo: os Cursos de Licenciatura em Educação do Campo. Nesse ínterim, a noção foucaultiana de governamentalidade é tomada de forma relevante para evidenciar as práticas inscritas em um dispositivo que opera por meio de múltiplas estratégias visando ao governamento de todos e de cada um. No entanto, em que consiste a governamentalidade em um registro foucaultiano? 
Na obra Segurança, Território, População, que reúne as aulas ministradas por Michel Foucault no Collège de France (1977-1978), o filósofo prossegue a discussão já iniciada em cursos anteriores sobre as tecnologias de poder exercidas sobre a vida e sobre o que ele chama de "personagem político absolutamente novo" no século XVIII: a população (FOUCAULT, 2008, p. 87). Para Foucault, naquele período, a população passa a ser tomada como "um conjunto de processos que é preciso administrar no que têm de natural e a partir do que têm de natural" (FOUCAULT, 2008, p. 92).

Ao discutir a emergência do conceito de população, Foucault (2008) problematiza as formas de poder e regulação que passam a operar sobre ela com o propósito de melhor governá-la. Nesse ponto, o filósofo introduz o conceito de governamentalidade para abordar as diversas maneiras de governar, destacando "o governo de si mesmo, que pertence à moral; a arte de governar uma família como convém, que pertence à economia; enfim a 'ciência de bem governar' o Estado, que pertence à política” (FOUCAULT, 2008, p. 125).

A noção de "governo" é amplamente discutida por Foucault (2008), mostrando os diferentes sentidos que podem ser atribuídos ao uso desta expressão. Referindo-se ao governo dos homens, o filósofo destaca que essa noção pode ser buscada no Oriente e sob duas formas: "primeiramente, sob a forma da ideia e da organização de um poder de tipo pastoral, depois sob a forma da direção de consciência, da direção das almas" (FOUCAULT, 2008, p. 166).

As noções de governo e de governamentalidade, de acordo com Castro (2009), estão no centro da obra de Foucault. "Quanto à noção foucaultiana de governo, ela tem, para expressá-lo de alguma maneira, dois eixos: o governo como relação entre sujeitos e o governo como relação consigo mesmo" (CASTRO, 2009, p. 190). Pode-se dizer que, no primeiro eixo, considera-se governar no sentido de conduzir condutas de um grupo ou indivíduo. E, no segundo eixo, são enfatizadas as relações estabelecidas consigo mesmo, na medida em que se trata de dominar prazeres e desejos. Em nosso artigo estamos usando a noção foucaultiana do primeiro eixo, ou seja, governar no sentido de conduzir condutas de um grupo ou indivíduo.

Essa ferramenta - a governamentalidade - nos possibilita conceber o Pronacampo e o conjunto de ações que dele são engendradas como mecanismos de regulação e controle das condutas dos sujeitos. Uma dessas ações é a criação e expansão dos Cursos de Licenciatura em Educação do Campo $^{2}$ no País (DUARTE; SANTOS,

\footnotetext{
Segundo Duarte e Santos (2015), em 2007, ocorreu a promoção de Licenciaturas em Educação do Campo no país, em caráter experimental, por meio de editais específicos, em quatro universidades: Universidade Federal de Brasília (UNB), Universidade Federal da Bahia (UFBA), Universidade Federal de Minas Gerais (UFMG) e Universidade Federal de Sergipe (UFS).
}

2015; SACHS; ELIAS, 2016), lócus de nosso estudo. Estes cursos são realizados pelas Universidades Federais e Institutos Federais de Educação, Ciência e Tecnologia em regime de alternância: tempo-universidade e tempocomunidade $^{3}$. Oferecem habilitação para docência multidisciplinar nos Anos Finais do Ensino Fundamental e Ensino Médio em uma das áreas: linguagens e códigos, ciências humanas, ciências da natureza, matemática e ciências agrárias.

Por ser uma política pública presente em todas as regiões do país, envolvendo professores e estudantes interessados nos processos educativos das escolas do campo e as comunidades onde essas instituições se localizam, os Cursos de Licenciatura em Educação do Campo têm sido objeto de pesquisas recentes como as de Molina e Hage (2016), Sá (2016) e Angelo (2013). Nosso artigo se aproxima desses estudos pelo fato de examinar enunciações de acadêmicos do referido Curso sobre a escola do campo. Porém, a diferença está nas lentes teóricas adotadas e no lócus da investigação, que será apresentado na próxima seção.

\section{Metodologia}

A parte empírica da investigação foi realizada com acadêmicos do Curso de Licenciatura em Educação do Campo, da Universidade Federal do Rio Grande do Sul (UFRGS). Como previsto no Projeto Político Pedagógico do Curso, o licenciado está habilitado a atuar: na disciplina de Ciências, nos Anos Finais do Ensino Fundamental; nas disciplinas de Química, Física e Biologia, no Ensino Médio; na Modalidade Educação de Jovens e Adultos e na Educação Profissional. Também poderá executar projetos de desenvolvimento sustentável utilizando a agroecologia. Em relação à estrutura curricular, o curso caracteriza-se pela pedagogia da alternância, dividindo os períodos de formação entre o "Tempo Comunidade" e o "Tempo Universidade".

O material de pesquisa examinado neste estudo é composto por documentos do Curso (como o Projeto Político Pedagógico e as ementas das disciplinas) e questionários aplicados em todas as turmas. Esse questionário visava, além de conhecer elementos das trajetórias escolar e profissional dos acadêmicos, identificar suas concepções sobre uma escola do campo. Para tanto, os passos percorridos na parte empírica iniciaram no estabelecimento de um contato com o coordenador do Curso para esclarecer os propósitos da

\footnotetext{
Entende-se por Tempo-universidade o periodo de formação presencial na Universidade ou Instituto que está ofertando a Licenciatura; já por TempoComunidade compreende-se a formação presencial nas comunidades camponesas, com a realização de práticas pedagógicas orientadas pelos docentes do Curso (BRASIL, 2013a).
} 
investigação. Após sua concordância, procurou-se pelos professores das referidas turmas de alunos a fim de explicar, novamente, os objetivos da pesquisa e acertar um horário para encontro com os estudantes. No momento da aplicação dos questionários, três turmas frequentavam a Licenciatura em Educação do Campo, em Porto Alegre: a primeira, com ingresso em 2014, possuía seis alunos; a segunda, com entrada em 2015, tinha 24 alunos; e a terceira, com ingresso em 2016, era composta por 49 alunos.

Importante salientar que este curso foi oferecido como um Programa Especial de Graduação para atender profissionais em exercício na Rede Pública de Ensino. Assim, como um Programa, a seleção, o número de vagas e a forma pela qual os semestres se organizam seguem editais específicos, e não a sequência prevista para os demais cursos de graduação da universidade, cujo ingresso dos alunos ocorre via vestibular. A evasão e a ausência às aulas que ocorrem no "Tempo Universidade" se constituem em uma marca da Licenciatura do Campo. Isso se deve, basicamente, à dificuldade dos estudantes em organizar seus horários de trabalho (e a liberação do mesmo) para frequentar as aulas que ocorrem, de forma intensiva, em uma ou duas semanas, a cada bimestre, na Faculdade.

Nos dias em que os questionários foram aplicados, nem todos os alunos matriculados estiveram presentes. Assim, obtivemos ao todo 47 questionários. A análise quantitativa desse material mostrou que todos os estudantes do Curso residem na região metropolitana de Porto Alegre. Predominam moradores da zona urbana, sendo que apenas uma aluna reside em uma comunidade quilombola e outra em um assentamento. Examinando a trajetória acadêmica dos estudantes, verificou-se que $61 \%$ do grupo não possuía formação anterior na área da Educação, ou seja, 36\% dos alunos não mencionaram outra formação e $25 \%$ do grupo declararam ter frequentado Cursos Técnicos Profissionalizantes em áreas como Agropecuária, Logística, Segurança do Trabalho, Eletrônica, Meio Ambiente, Auxiliar de Empresa e Gestão - RH. Apenas um aluno possuía Curso Superior completo, no caso, em Administração de Empresas.

Os demais estudantes possuíam vínculo (anterior ou atual) com a área da Educação. Desses, alguns declararam que iniciaram Curso Superior em diferentes Licenciaturas como História, Pedagogia, Ciências Naturais, Educação Física, Biologia e Letras, mas não concluíram, basicamente, por problemas financeiros. Atuavam como professor apenas nove acadêmicos do Curso: três nos Anos Iniciais do Ensino Fundamental, um na área de História e cinco afirmaram ser professores em escolas do campo.

A estratégia analítica posta em ação para operar com o material de pesquisa reunido foi orientada pela análise do discurso em uma perspectiva foucaultiana. Na ocasião de uma entrevista concedida a Claude Bonnefoy, em 1968, Foucault (2016, p. 42) expressou que sua preocupação, nos últimos dez anos, era entender o que seria, em uma cultura como a nossa, em uma sociedade, "a existência das falas, da escrita, do discurso". Dando continuidade a sua linha de pensamento, o filósofo argumentou que "os discursos não são apenas uma espécie de película transparente através da qual se veem as coisas, não são simplesmente o espelho daquilo que se pensa" (FOUCAULT, 2016, p.42). Nesse sentido, os discursos - tal como recorrentemente é citado, quando a arquitetura de uma pesquisa é constituída a partir da análise do discurso na clave foucaultiana - são "práticas que formam sistematicamente os objetos de que falam" (FOUCAULT, 2002, p. 56).

Nosso interesse ao examinar o material produzido na investigação a partir do pensamento foucaultiano alinha-se ao questionamento proposto pelo filósofo: “[...] me interrogo é sobre o modo de aparição e de funcionamento do discurso real, sobre as coisas que foram efetivamente ditas. Trata-se de uma análise das coisas ditas na medida em que são coisas" (FOUCAULT, 2002, p. 43). Assim, tendo em mãos os questionários e os documentos do curso, nossa pretensão foi dar visibilidade e examinar as recorrências, isto é, buscar pelos enunciados que se faziam presentes naquilo que os alunos escreveram e no que líamos no PPP do Curso.

Os enunciados, seguindo aquilo que aprendemos com Foucault e alguns de seus comentadores, como Deleuze (2006), Veiga-Neto (2003) e Fischer (2012), não seriam palavras, frases ou proposições, mas formações que se fazem visíveis quando os sujeitos das frases, os objetos da proposição e os significados das palavras mudam de natureza. Isso ocorre quando esses elementos tomam o lugar do "diz-se", distribuindo-se, dispersando-se na espessura da linguagem (DELEUZE, 2006). Isso possibilita, como argumenta Fischer (2012, p. 103), questionar “[...] como algumas práticas acabam por objetivar e nomear de determinada forma os sujeitos, os grupos, suas ações, gestos, vidas". No caso desse trabalho, podemos refletir o quanto as ideias que circulam sobre escola do campo se fazem presentes naquilo que dizem os licenciandos. Não só naquilo que dizem, mas naquilo que pode direcionar suas formas de conceber as escolas do campo, suas ações e gestos como futuros educadores.

Vale ressaltar que esse trabalho minucioso de vasculhar os questionários, o Projeto Político Pedagógico do Curso e as ementas das disciplinas em busca do que era recorrente, isto é, de fazer perceptíveis os enunciados, descobrindo seus pedestais, polindo-os, moldando-os e até mesmo inventando-os (DELEUZE 2006), não tínhamos a priori um local de chegada. Guiadas por Foucault, 
nosso exercício investigativo foi a tentativa de ver o que ainda não tínhamos visto, de fazer um diagnóstico sobre a escola do campo. Aqui tomamos emprestadas as ideias do filósofo:

No fundo, não escrevo porque tenho alguma coisa na cabeça, não escrevo para demonstrar aquilo que já, em meu foro interior e para mim mesmo, demonstrei e analisei. A escrita consiste essencialmente em empreender uma tarefa graças à qual e ao final da qual poderei, para mim mesmo, encontrar alguma coisa que não tinha visto inicialmente. Quando começo a escrever um estudo, um livro, qualquer coisa, não sei realmente aonde isso vai, nem em que vai dar, nem o que demonstrarei. Só descubro o que tenho para demonstrar no próprio movimento da escrita, como se escrever fosse precisamente diagnosticar aquilo que queria dizer no exato momento em que comecei a escrever (FOUCAULT, 2016, p. 49).

Inspiradas por essas palavras, podemos dizer que foi no próprio movimento da escrita, sustentada pelas teorizações foucaultinas, que descobrimos aquilo que "te[mos] para demonstrar" sobre as enunciações dos estudantes da Licenciatura em Educação do Campo e aquelas presentes nos documentos examinados. Essa demonstração será apresentada na próxima seção.

\section{A ESCOLA do CAMPO, A GESTÃ̃o DO RISCO E A GUETIZAÇÃO DO PROCESSO PEDAGógICO}

A análise do material evidenciou algumas recorrências sobre as concepções dos acadêmicos do Curso de Licenciatura sobre a escola do campo. Nos questionários, em especial, quando solicitados a escrever sobre uma escola que atende crianças e jovens das zonas rurais, eles expressaram a necessidade de valorizar a cultura presente no campo, levando em conta, no processo de escolarização, principalmente, a "realidade" do grupo atendido ${ }^{4}$ :

Pra mim uma escola do Campo tem que ter, além de estrutura, salas, pessoal, mas tem que ser uma escola viva, ligada a realidade dos alunos e para isso acontecer todos, todos, tem que conhecer as famílias dos alunos, as pessoas que ali trabalham precisam querer estar

\footnotetext{
${ }^{4}$ Nesta seção, transcrevemos trechos dos depoimentos presentes nos questionários aplicados nas turmas do Curso. Como os questionários não foram identificados, seguindo os princípios éticos das pesquisas em Educação, os excertos apresentados serão identificados como "participante X", sendo que X é um número utilizado como forma de ordenar o material dos estudantes. À medida em que recebíamos os questionários, marcávamos neles números em ordem crescente partindo do 1 . Desta forma, os questionários e, consequentemente, os depoentes foram sendo identificados: "participante 1", "participante 2", "participante 3" e, assim, sucessivamente.
}

ali, respeitar aquelas pessoas e incentivar as crianças para todas as possibilidades que existem no mundo (Participante 6) ${ }^{5}$.

A escola do campo deveria ser mais próxima à realidade do campo. Abranger os conhecimentos necessários e de acordo com os saberes e a cultura desse povo. Utilizar métodos que sejam reconhecidos por eles. Há diferenças entre a escola do campo e da cidade. A escola da cidade é voltada para a formação profissional, e do campo utiliza os saberes já existentes e através de metodologia deve ensinar respeitando a cultura já existente (Participante 8$)^{6}$.

[A escola do campo é] um território, um espaço no qual valorize a trajetória daquele indivíduo empoderando-o. Resgatando aquela cultura daquele campo. Sim, há uma diferença, os indivíduos e cada comunidade e grupo tem que ter uma metodologia, uma maneira de lecionar (Participante 8) ${ }^{7}$.

Uma escola do campo deve dialogar com o contexto e realidade das populações e povos do campo. Para além dos conteúdos que dizem ser essencial para a aprendizagem, tem que dialogar com os saberes culturais existentes (Participante 12) ${ }^{8}$.

Os excertos selecionados evidenciam que a escola do campo precisa estar "ligada à realidade", "próxima" do campo, mantendo "diálogo" com os saberes culturais dos alunos. Para isso, é preciso, nas palavras dos estudantes, conhecer as famílias presentes nas escolas, utilizar metodologias que sejam reconhecidas pelos discentes e valorizar suas trajetórias individuais. Chama a atenção a recorrência da ideia de que a escola do campo "deve" trabalhar com a forma de vida do campo.

Do mesmo modo, a vida no campo e o tipo de trabalho ali realizado parece ser entendido de uma forma diferente daquele do meio urbano. Os saberes que circulam na forma de vida do campo, no dizer dos licenciandos, não precisam de uma "validação acadêmica", ao contrário dos saberes necessários ao mundo do trabalho do meio urbano. Como descreveu uma das participantes da pesquisa: "a escola da cidade é voltada para a formação profissional e a do campo utiliza os saberes já existentes e através de

\footnotetext{
Depoimento coletado por meio de questionário aplicado no dia 18 de maio de 2017, na cidade de Porto Alegre, Rio Grande do Sul, Brasil, à pesquisadora Fernanda Wanderer.

${ }^{6}$ Depoimento coletado por meio de questionário aplicado no dia 18 de maio de 2017, na cidade de Porto Alegre, Rio Grande do Sul, Brasil, à pesquisadora Fernanda Wanderer.

7 Depoimento coletado por meio de questionário aplicado no dia 18 de maio de 2017, na cidade de Porto Alegre, Rio Grande do Sul, Brasil, à pesquisadora Fernanda Wanderer.

8 Depoimento coletado por meio de questionário aplicado no dia 18 de maio de 2017, na cidade de Porto Alegre, Rio Grande do Sul, Brasil, à pesquisadora Fernanda Wanderer.
} 
metodologia deve ensinar respeitanto a cultura existente" (Participante 26) .

Lendo atentamente as Diretrizes Curriculares Nacionais para a Educação do Campo (BRASIL, 2013a), bem como documentos do Pronacampo (BRASIL, 2013b) e do Curso de Licenciatura percebemos que há a constituição de uma verdade relacionada à ideia de que as escolas do campo precisam contemplar a realidade do campo. Essa verdade, no sentido analisado por Foucault (2003), encontra sustenção em diferentes enunciações presentes nos materiais escrutinados e em documentos oficiais. Excertos das Diretrizes Curriculares Nacionais evidenciam essa questão:

[...] a identidade da escola do campo é definida pela sua vinculação com as questões inerentes à sua realidade, ancorando-se na temporalidade e saberes próprios dos estudantes, na memória coletiva que sinaliza futuros, na rede de ciência e tecnologia disponível na sociedade e nos movimentos sociais em defesa de projetos que associem as soluções exigidas por essas questões à qualidade social da vida coletiva no País. [...].

A educação para a população rural está prevista no artigo 28 da LDB, em que ficam definidas, para atendimento à população rural, adaptações necessárias às peculiaridades da vida rural e de cada região, definindo orientações para três aspectos essenciais à organização da ação pedagógica: I - conteúdos curriculares e metodologias apropriadas às reais necessidades e interesses dos estudantes da zona rural; II - organização escolar própria, incluindo adequação do calendário escolar às fases do ciclo agrícola e às condições climáticas; III - adequação à natureza do trabalho na zona rural. [...].

As propostas pedagógicas das escolas do campo devem contemplar a diversidade do campo em todos os seus aspectos: sociais, culturais, políticos, econômicos, de gênero, geração e etnia. Formas de organização e metodologias pertinentes à realidade do campo devem, nesse sentido, ter acolhida (BRASIL, 2013a, p.45).

Além das Diretrizes, consideramos pertinente destacar também alguns fragmentos presentes na Portaria $\mathrm{n}-86$, de 1ㅇ de fevereiro de 2013 (BRASIL, 2013b), que institui o Pronacampo. No texto é expresso que os princípios da educação do campo consistem em:

respeito à diversidade do campo em seus aspectos sociais, culturais, ambientais, políticos, econômicos, de gênero, geracional e de raça e etnia; [...] incentivo à formulação de projetos politico-pedagógicos

\footnotetext{
9 Depoimento coletado por meio de questionário aplicado no dia 25 de maio de 2017, na cidade de Porto Alegre, Rio Grande do Sul, Brasil, à pesquisadora Fernanda Wanderer.
}

específicos para as escolas do campo; [...] valorização da identidade da escola do campo por meio de projetos pedagógicos com conteúdos e metodologias adequadas às reais necessidades dos alunos do campo (BRASIL, 2013b, p. 4-5).

Também no Projeto Político Pedagógico do Curso de Licenciatura (UFRGS, 2013) aqui examinado e em algumas ementas de disciplinas, observa-se uma forte alusão à importância de que as escolas do campo trabalhem com essa forma de vida:

\begin{abstract}
A proposta curricular do curso possibilitará que o licenciando vivencie em seu cotidiano acadêmico a valorização e a produção de conhecimentos e saberes contextualizados no mundo da vida rural, em particular os mundos do trabalho docente e do Campo (UFRGS, 2013, p. 4-5).
\end{abstract}

Constituição da docência, a partir da investigação de conhecimentos técnicocientíficos, de saberes advindos do exercício profissional escolar e de práticas socioculturais que se articulam com questões inerentes à realidade do campo. Possibilidades de recriação de uma docência peculiar do/no campo (UFRGS, 2013, p. 22).

Estudo do pensamento educacional curricular, com ênfase na perspectiva do currículo como produção cultural. Investigação de saberes e práticas da vida e trabalho no campo, visando possibilidades de instituílos como conteúdos escolares (UFRGS, 2013, p. 34).

Os excertos selecionados nos ajudam a pensar em, pelo menos, duas questões. Uma delas diz respeito à constituição da escola do campo fortemente vinculada às formas de vida do campo. Que escola seria essa? Os acadêmicos e os documentos examinados enunciam: uma instituição que aborde saberes, práticas e metodologias específicas às necessidades e interesses dos estudantes do campo, cujo calendário também se ajuste "às fases do ciclo agrícola e às condições climáticas" (BRASIL, 2013a, p. 45).

Além disso, é preciso que na escola sejam trabalhados vários elementos da forma de vida do campo, provenientes de questões sociais, culturais, políticas, econômicas, envolvendo ainda os marcadores de gênero, geração e etnia. Para isso, é necessário que os docentes investiguem conhecimentos próprios da vida camponesa para "instituí-los como conteúdos escolares" (UFRGS, 2013, p. 34). Ou seja, nos interessa mostrar o quanto a escola do campo é concebida como uma instituição específica, voltada aos interesses e necessidades da comunidade na qual se insere.

A segunda questão relaciona-se aos fortes entrelaçamentos entre as enunciações presentes nos 
documentos examinados com aquilo que dizem os alunos (das três turmas) do curso. Chama a atenção que a menção à relevância da escola do campo trabalhar com a realidade, contexto ou especificidade do campo foi recorrente nas três turmas de alunos, não sendo possível identificar diferenças, nesse sentido, entre as enunciações daqueles que estão nas etapas finais com aqueles que frequentam os semestres iniciais. Isso nos leva a pensar que os acadêmicos estão capturados pelo enunciado que diz que a escola do campo deve trabalhar com a forma de vida do campo.

Podemos entender a recorrência desse enunciado de diferentes modos. Entre eles, a de que essa valorização atende a uma urgência, ou seja, manter no campo a população do campo. Isso pode ser evidenciado, por exemplo, no parecer no 36 de 4 de dezembro de 2001, que trata das Diretrizes Operacionais para a Educação Básica nas Escolas do Campo (BRASIL, 2001). Dentre as razões elencadas para a aprovação do documento, destaca-se que a forma de vida do campo - a partir do olhar de estudiosos - tenderia a desaparecer:

Por sua vez, a partir de uma visão idealizada das condições materiais de existência na cidade e de uma visão particular do processo de urbanização, alguns estudiosos consideram que a especificidade do campo constitui uma realidade provisória que tende a desaparecer, em tempos próximos, face ao inexorável processo de urbanização que deverá homogeneizar o espaço nacional. Também as políticas educacionais, ao tratarem o urbano como parâmetro e o rural como adaptação reforçam essa concepção (BRASIL, 2001, p. 2, grifos nossos).

Examinando esse trecho do parecer, podemos dizer que há uma crítica ao modelo vigente de escola que, ao tratar o urbano como parâmetro e o rural como uma adaptação, reforçariam essa visão de que o campo está em extinção. Esse modelo também está presente nas escritas dos estudantes do curso que apregoam a necessidade de aproximar a escola geograficamente situada no campo, com "a realidade" da forma de vida do campo. Parece haver um esforço para manter "viva" a cultura do campo, através de uma escola "viva", que residiria na "realidade" dos alunos. Como descreveu uma das participantes da pesquisa: “[...] tem que ser uma escola viva, ligada à realidade dos alunos [...]" (Participante 23) ${ }^{10}$.

Isso, de certo modo, conecta-se à discussão tecida por Bauman (2009) acerca da cidade. Trazendo ao seu texto diferentes autores, o sociólogo polonês edifica seus apontamentos cercando-se em diferentes pesquisas que mostram que a falta de trabalho para todos no campo

\footnotetext{
${ }^{10}$ Depoimento coletado por meio de questionário aplicado no dia 25 de maio de 2017, na cidade de Porto Alegre, Rio Grande do Sul, Brasil, à pesquisadora Fernanda Wanderer.
}

e o fenômeno da globalização teriam a ver com um progressivo deslocamento das populações do campo para o espaço urbano. Tomando o exemplo do Canadá, Bauman (2009) escreve que um levantamento em Ontário indicou que a cada ano, com o crescente investimento em tecnologia por parte dos agricultores, é preciso menos gente para produzir. Desse modo, entre 1998 e 2002, “[...] desapareceram das estatísticas de Ontário 35 mil trabalhadores que o 'progresso tecnológico' tornou supérfluos, substituídos por novas tecnologias, melhores que as precedentes (pois são capazes de reduzir ainda mais a mão-de-obra)" (BAUMAN, 2009, p. 58).

O sociólogo prossegue em sua discussão atentando para o fato de que ainda que o incremento na produção, com a diminuição de gastos, possa ter enriquecido a Ontário rural e melhorado a vida de alguns agricultores, não há sinal de maior opulência, fator devido principalmente à globalização. Apoiado em Van Donkersgoed, Bauman (2009, p. 58) destaca que a globalização gerou uma "estrutura feita de fusões e aquisições por parte das empresas" que fornecem praticamente tudo aquilo que os agricultores necessitam. Disso resultaria que os lucros de uma maior produtividade saem das mãos dos trabalhadores para essas grandes corporações que se apoderam do mercado, usando seu poder econômico para obter tudo o que pretendem dos agricultores, acabando inclusive com o comércio espontâneo, ou seja, a troca de mercadorias entre iguais (BAUMAN, 2009, p.59).

Outro exemplo que trazemos ao texto por empréstimo de Bauman (2009) é o da Namíbia, um país que, segundo as estatísticas, possui maior bem-estar econômico do continente africano. Na Namíbia, tradicionalmente um país de camponeses, observa-se um grande decréscimo de sua população rural, ao mesmo tempo em que a população da capital duplicou (BAUMAN, 2009). Esse acúmulo populacional nas periferias da cidade, sem renda ou emprego, teria a ver com a liberação do excesso de mão de obra agrícola, fruto do crescimento da produtividade na agricultura. Assim como no caso de Ontário, os grandes lucros não teriam ficado no campo ou mesmo sido realocados para as cidades. Mais uma vez, isso seria resultado do processo de globalização.

\footnotetext{
Naqueles lugares do planeta que sofrem as pressões da globalização, 'as cidades transformaram-se em campos de refugiados para os que foram expulsos da agricultura', observa Jeremy Seabrook, que em seguida descreve a vida urbana que os expulsos da vida rural parecem encontrar: sem ninguém que lhes ofereça trabalho, transformando-se em condutores de riquixás ou empregados domésticos; compram algumas bananas e colocam no chão, na esperança de vendê-las; transformam-se em carregadores de malas ou serventes (BAUMAN, 2009, p. 60).
} 
As cidades, segundo Bauman (2009), teriam sido organizadas com o intuito de manter o perigo afastado. Hoje, ao invés de representarem defesas contra o perigo, elas estão se convertendo em perigo. E esse perigo teria a ver com todo um contingente de pessoas que, desprovidas dos meios para participar de forma efetiva dos jogos de consumo acumulam-se nas periferias. De certo modo, então, manter as populações do campo no campo tem a ver com a gestão do risco, ou seja, o risco de receber um excedente cada vez maior de expulsos da vida rural para engrossar o "campo de refugiados" de que fala Bauman. Os riscos que acompanham o esvaziamento do campo e o consequente inchaço das periferias das cidades devem ser alvo de uma gestão própria.

Tomando como apoio as teorizações de Foucault, Fimyar (2009) destaca que essa busca pela segurança por meio da gestão de risco é um problema próprio do governo. Sendo a população a fonte do Estado, para governar adequadamente e garantir sua otimização, faz-se necessário que o governo se estabeleça como um governo econômico, tanto no diz respeito às finanças, quanto no que concerne à sua forma de exercer poder. $\mathrm{O}$ liberalismo, enquanto racionalidade governamental, tem, na "segurança" do desenvolvimento socioeconômico da população, sua preocupação fundamental, tendo em vista que a segurança da população é a base da prosperidade do Estado (FIMYAR, 2009). Visando a alcançar essas metas, "[...] o Estado liberal enquadra sua população aos aparatos de segurança - de um lado, o exército, a polícia e os serviços de inteligência; de outro, a educação, a saúde e o bem-estar" (FIMYAR, 2009, p. 40).

Ao analisarem a inclusão a partir de políticas públicas de assistência social no Brasil, Lopes et al. (2010, p.8) consideraram tais políticas como estratégicas biopolíticas de gerenciamento do risco social, afirmando que "elas objetivam garantir a segurança da população através dos programas e ações que colocam em funcionamento". Como as autoras argumentam, no Brasil, atualmente, proliferam tais políticas. Desse modo, "não são poucos os benefícios e programas sociais disponibilizados atualmente para a população carente, assim como também não é pequeno o número de famílias beneficiadas" (LOPES et al., 2010, p. 8). São diversos programas sociais, tais como o Bolsa Família, o Pró-Jovem, o Pró-Uni, o Salário-Desemprego, entre outros, que "objetivam auxiliar aquelas camadas da população brasileira que não conseguem, por si mesmas, gerenciar suas vidas ou prevenir os riscos de sua própria existência" (LOPES et al., 2010, p.8).

Em suma, como mostram as autoras, essas ações devem ser pensadas não apenas como políticas de inclusão social que visam a assegurar as necessidades básicas de sobrevivência de seus beneficiários, mas como formas de garantir a inserção desses sujeitos nos jogos do mercado.
Tal inclusão possibilita o gerenciamento e a prevenção de possíveis riscos que essas camadas da população podem oferecer para a vida coletiva (LOPES et al., 2010).

Essas considerações levam-nos a afirmar que o governamento operacionalizado por estratégias como aquelas preconizadas no Pronacampo são também colocadas em curso pelo Estado, tomando como alvo o gerenciamento dos riscos subjacentes à baixa escolaridade dessa população e ao desaparecimento dos vestígios da forma de vida do campo - que, por isso, poderia acabar "fora do campo". Tal governamento dá-se pela condução da conduta de todos e de cada um. Porém, vale ressaltar que a condução da conduta não se efetiva de forma imposta ou violenta. Ela ocorre em relação a sujeitos que se deixam conduzir. Isso também envolve a captura da alma, do desejo e do interesse de todos e de cada um.

Nesse sentido, podemos dizer que todo aparato disposto pelos documentos que embasam a Educação do campo no Brasil hoje, a formação docente voltada para a atuação na escola do campo e boa parte da literatura voltada para esse segmento, captura a alma, os desejos e o interesse de todos. Assim, os sujeitos acabariam sendo envolvidos em tramas que posicionariam a "realidade" do campo como meio e objetivo de práticas pedagógicas "eficientes".

Em outra aproximação com o pensamento de Bauman (2003), podemos dizer que essa valorização da forma de vida do campo tão presente nos escritos dos participantes da pesquisa e nos documentos que conformam o Curso de Licenciatura em Educação do Campo poderia ser pensada como um processo de guetização. Entretanto, ao contrário dos verdadeiros guetos, que combinariam o confinamento espacial com o fechamento social, seria uma tentativa de se estabelecer guetos voluntários que difeririam dos verdadeiros em um aspecto decisivo:

\begin{abstract}
Os guetos reais são lugares dos quais não se pode sair (como diz Wacquant, os habitantes dos guetos norteamericanos 'não podem casualmente atravessar para o bairro branco adjacente, sob pena de serem seguidos e detidos, quando não hostilizados, pela polícia'); o principal propósito do gueto voluntário, ao contrário, é impedir a entrada de intrusos - os de dentro podem sair à vontade (BAUMAN, 2003, p. 106).
\end{abstract}

Aqui não falamos de uma guetização do espaço, mas do processo pedagógico. O material produzido na pesquisa nos leva ao entendimento de que a educação do campo deveria ser constituída dentro dos limites seguros do saber forjado nas relações que os sujeitos do campo alicerçam todos os dias em suas formas de vida. Desse modo, nos dizeres dos estudantes, "a escola do campo deveria ser mais próxima à realidade do campo, abranger os conhecimentos necessários e de acordo com os saberes 
e cultura desse povo" (Participante 9) ${ }^{11}$. Assim, "uma escola do campo deve dialogar com o contexto e realidade das populações e povos do campo [...] tem que se dialogar com os saberes culturais existentes" (Participante 21) ${ }^{12}$. $\mathrm{Ou}$, ainda, como outro estudante discorreu: "a escola do campo deve deliberar sobre seu conteúdo, metodologias e modos de ser juntamente com a comunidade que está inserida, com os educandos, pais e responsáveis" (Participante 7) ${ }^{13}$.

Diríamos até que, no limite, alguns acadêmicos expressam que a escola do campo poderia exercer um "autogerenciamento", realizando seu trabalho pedagógico de forma a seguir somente aquilo que faz parte do modo de vida da comunidade onde está inserida. Como escreveu um acadêmico: "a escola do/no campo deveria ser como os sujeitos que vivem e trabalham acham que deveria ser" (Participante 30) ${ }^{14}$. Outro aluno, na mesma direção, expressou: "A escola do campo deve seguir as diretrizes apresentadas no PPP, mas deve poder organizar seu currículo e se organizar de forma independente, respeitando os povos do campo" (Participante 32$)^{15}$.

Nesse gueto "pedagógico" formulado pelos licenciandos parece haver pouco espaço para se ir além do que a "realidade" dos alunos das escolas do campo permite. Esse "além" não estaria interditado, mas não foi mencionado nos questionários gerados em nossa pesquisa.

\section{CONSIDERAÇÕES FINAIS}

Nesta seção, que encerra o artigo, temos o propósito de elencar algumas reflexões que o estudo realizado nos possibilita ainda apresentar. Com o objetivo de examinar as enunciações sobre a escola do campo produzidas por acadêmicos de um Curso de Licenciatura em Educação do Campo, o trabalho mostrou que os discentes estão capturados pelo enunciado que diz: "a escola do campo deve trabalhar com a forma de vida do campo". Esse enunciado sustenta-se, basicamente, em duas recorrências encontradas no material examinado: uma valorização exacerbada da cultura do campo e certa guetização do processo pedagógico, o qual "deve estar" vinculado às

\footnotetext{
${ }^{11}$ Depoimento coletado por meio de questionário aplicado no dia 18 de maio de 2017, na cidade de Porto Alegre, Rio Grande do Sul, Brasil, à pesquisadora Fernanda Wanderer.

12 Depoimento coletado por meio de questionário aplicado no dia 25 de maio de 2017, na cidade de Porto Alegre, Rio Grande do Sul, Brasil, à pesquisadora Fernanda Wanderer.

${ }^{13}$ Depoimento coletado por meio de questionário aplicado no dia 18 de maio de 2017, na cidade de Porto Alegre, Rio Grande do Sul, Brasil, à pesquisadora Fernanda Wanderer.

${ }^{14}$ Depoimento coletado por meio de questionário aplicado no dia 25 de maio de 2017, na cidade de Porto Alegre, Rio Grande do Sul, Brasil, à pesquisadora Fernanda Wanderer.

${ }^{15}$ Depoimento coletado por meio de questionário aplicado no dia 25 de maio de 2017, na cidade de Porto Alegre, Rio Grande do Sul, Brasil, à pesquisadora Fernanda Wanderer
}

formas de vida do campo. Isso nos leva a pensar que há, no âmbito escolar, certa conformação que visa a conduzir a conduta dos sujeitos que vivem no campo a permanecer e estudar essa forma de vida. Como anunciamos no início desse texto, tal conformação, materializada nos documentos sobre a educação do campo e nas enunciações dos futuros educadores, faz parte de um dispositivo de governamento das populações do campo.

Ao mesmo tempo, não podemos deixar de observar que essa valorização exacerbada da cultura do campo e a consequente guetização do processo pedagógico (restrita aos saberes e práticas dessas culturas) está alicerçada em uma discursividade pedagógica redutora, que pouco ou nada "escapa" para além da "realidade" dos educandos. Essa forma de conceber a educação tem sido objeto de problematizações, como discutem Masschelein e Simons (2017), no livro Em defesa da escola. Os autores constroem uma argumentação que, em oposição ao que observamos no material de pesquisa examinado, atribui outros significados ao processo pedagógico, tirando o foco de uma suposta "realidade" do educando ou da comunidade onde a escola está inserida para o estabelecimento de práticas capazes de tornar diferentes disciplinas, como a matemática ou a marcenaria, importantes por si mesmas. Para eles, educar não é apenas abordar ou partir das formas de vida dos estudantes, mas apresentar "as coisas do mundo (matemática, inglês, culinária, marcenaria)" e possibilitar às crianças e aos jovens o "contato com essas coisas, colocando-os em sua companhia, para que essas coisas - e, com elas, o mundo - comecem a se tornar significativas para eles" (MASSCHELEIN; SIMONS, 2017, p.99).

Em outro momento, Masschelein e Simons (2017) também questionam a insistência das práticas pedagógicas contemporâneas na importância da prática e da utilidade dos conteúdos escolares que, ao se tornarem parte do currículo, tenderiam a se converter em quimeras perdendo toda a ligação concreta com a realidade. Esse contraste entre o que apregoam Masschelein e Simons (2017) sobre a escolarização e o que evidenciamos nesse estudo poderia render uma produtiva discussão, o que nos mobiliza a seguir realizando estudos e investigações nessa área.

Para finalizar, consideramos pertinente destacar que nosso intuito não é dizer que não devemos valorizar a forma de vida dos sujeitos aos quais o processo educativo é endereçado. Ou ainda, dizer que tal processo deva ser padronizado a todos. Isso não seria coerente com nossas posições políticas e pedagógicas. A intencionalidade dessa reflexão reside em pensar o impensável em educação, entender o que faz com que algo se materialize nas falas e nas ações. E, com isso, relativizar algumas práticas adotadas desde sempre, sem questionamento. Trata-se, aqui, de refletir acerca dos 
limites e possibilidades de processos educativos traçados por diferentes discursividades pedagógicas, colocando em curso movimentos de resistência ao calcificado, ao concretado, ao estabelecido. É não seguir simplesmente o fluxo. É ir na contramão, provocadas pelo que escreveram Deleuze e Guattari (1992, p. 139): "falta-nos resistência ao presente".

\section{REFERÊNCIAS}

ANGELO, Aline Aparecida. O que é ser educador do campo: os sentidos construídos pelos estudantes do Curso de Licenciatura em Educação do Campo da FaE/UFMG. 2013. Dissertação (Mestrado em Processos Socioeducativos e Práticas Escolares) - Programa de Pós-Graduação em Processos Socioeducativos e Práticas Escolares, Departamento de Educação, Universidade Federal de São João Del-Rei, São João Del-Rei, 2013.

ARROYO, Miguel. Políticas de formação de educadores (as) do campo. Cadernos Cedes, Campinas, v. 27, n. 72, p. 157-176, maio/ago. 2007. https://doi.org/10.1590/S010132622007000200004

BAUMAN, Zygmunt. Comunidade: a busca por segurança no mundo atual. Rio de Janeiro: Jorge Zahar, 2003.

BAUMAN, Zygmunt. Confiança e medo na cidade. Rio de Janeiro: Jorge Zahar, 2009.

BRASIL. Ministério da Educação. Conselho Nacional de Educação. Parecer n⿳ ${ }^{0}$ 36, de 04 de dezembro de 2001. Diretrizes Operacionais para a Educação Básica nas Escolas do Campo. Brasília: Ministério da Educação, 2001. Disponível em: http://pronacampo.mec.gov.br/images/pdf/ mn_parecer_36_de_04_de_dezembro_de_2001.pdf. Acesso em: 15 jun. $\overline{2} 01 \overline{7}$.

BRASIL. Ministério da Educação. Diretrizes Curriculares Nacionais para Educação Básica. Brasília: MEC, 2013a. Disponível em: http://portal.mec.gov.br/docman/julho-2013pdf/13677-diretrizes-educacao-basica-2013-pdf/file. Acesso em: 20 jun. 2017.

BRASIL. Ministério da Educação. Portaria no 86, de 1ำ de fevereiro de 2013. Diário Oficial [da] República Federativa do Brasil: seção 1, Brasília, DF, n. 24, p. 28, 2013 b. Disponível em: http://pronacampo.mec.gov.br/images/pdf/ port_86_01022013.pdf. Acesso em: 15 jun. 2017.

CALDART, Roseli Salete. A escola do campo em movimento. In: BENJAMIN, César; CALDART, Roseli Salete (org.). Projeto popular e escolas do campo: articulação nacional por uma educação básica do campo. Brasília: Articulação Nacional Por uma Educação Básica do Campo, 2000. (Coleção Por uma Educação Básica do Campo, n. 3). p.26-57.

CALDART, Roseli Salete. A escola do campo em movimento. Currículo sem Fronteiras, [s.l.], v. 3, n. 1, p. 60-81, jan./jun. 2003.
CALDART, Roseli Salete. Por uma educação do campo: traços de uma identidade em construção. In: KLLING, Edgar Jorge; CERIOLI, Paulo Ricardo; CALDART, Roseli Salete (org.). Educação do Campo: identidades e políticas públicas. Brasília: Articulação Nacional Por uma Educação Básica do Campo, 2002. (Coleção Por uma Educação do Campo, n. 4). p. 18-25.

CASTRO, Edgardo. Vocabulário de Foucault. Belo Horizonte: Autêntica, 2009.

DELEUZE, Gilles. Foucault. São Paulo: Brasiliense, 2006.

DELEUZE, Gilles; GUATTARI, Felix. O que é filosofia? Rio de Janeiro: Editora 34, 1992.

DUARTE, Claudia G.; SANTOS, Simone V. Apresentação da seção temática - educação do campo. Educação \&

Realidade, Porto Alegre, v. 40, n. 3, p. 659-666, jul./set. 2015. https://doi.org/10.1590/2175-623656800

FIMYAR, Olena. Governamentalidade como ferramenta conceitual na pesquisa de políticas educacionais. Educação \& Realidade, Porto Alegre, v. 34, n. 2, p.35-56, maio/ago. 2009.

FISCHER, Rosa Maria Bueno. Trabalhar com Foucault: arqueologia de uma paixão. Belo Horizonte: Autêntica, 2012.

FOUCAULT, Michel. Arqueologia do saber. Rio de Janeiro: Forense Universitária, 2002

FOUCAULT, Michel. Microfísica do poder. Rio de Janeiro: Edições Graal, 2003.

FOUCAULT, Michel. O belo perigo. Belo Horizonte: Autêntica, 2016.

FOUCAULT, Michel. Segurança, território, população. São Paulo: Martins Fontes, 2008.

HAGE, Salomão M. Por uma escola do campo de qualidade social: transgredindo o paradigma (multi)seriado de ensino. Em Aberto, Brasília, v. 24, n. 85, p. 97-113, abr. 2011.

KNIJNIK, Gelsa. Educação Matemática, cultura e conhecimento na luta pela terra. Porto Alegre: UNISC, 2006.

KNIJNIK, Gelsa; WANDERER, Fernanda. Programa Escola Ativa, escolas multisseriadas do campo e educação matemática. Educação e Pesquisa, São Paulo, v. 39, n. 1, p.211-225, jan./ mar. 2013. https://doi.org/10.1590/S1517-97022013000100014

LOPES, Maura Corcini et al. Inclusão e biopolítica. São Leopoldo: Instituto Humanitas Unisinos, 2010.

MARÍN-DÍAZ, Dora Lilia. Autoajuda e educação: uma genealogia das antropotécnicas contemporâneas. 2012. Tese (Doutorado em Educação) - Programa de Pós-Graduação em Educação, Faculdade de Educação, Universidade Federal do Rio Grande do Sul, Porto Alegre, 2012.

MASSCHELEIN, Jan; SIMONS, Maarten. Em defesa da escola: uma questão pública. Belo Horizonte: Autêntica, 2017. 
MOLINA, Mônica Castagna; HAGE, Salomão Mufarrej. Riscos e potencialidades na expansão dos cursos de licenciatura em Educação do Campo. Revista Brasileira de Política e Administração da Educação, Goiânia, v. 32, n. 3, p. 805-828, set./dez. 2016. https://doi.org/10.21573/ vol32n32016.68577

SÁ, Josinalva R. Licenciatura em Educação do Campo: propostas em disputa na perspectiva de estudantes do Curso de Matemática da UFMG. 2016. Dissertação (Mestrado em Educação) - Programa de Pós-Graduação em Educação, Faculdade de Educação, Universidade Federal de Minas Gerais, Belo Horizonte, 2016.

SACHS, Línlya; ELIAS, Henrique R. A formação matemática nos cursos de licenciatura em educação do campo. Bolema, Rio Claro, v. 30, n. 55, p. 439-454, ago. 2016. https://doi. org/10.1590/1980-4415v30n55a07

UNIVERSIDADE FEDERAL DO RIO GRANDE DO SUL. Projeto Pedagógico do Curso de Graduação Licenciatura em Educação do campo: Programa Especial de Graduação - PEG. Porto Alegre: Faculdade de Educação, 2013. Disponível em: https://www.ufrgs.br/liceducampofaced/ wp-content/uploads/2017/05/PROJETO_PEDAGOGICO_ EDUCAMPO-4.pdf. Acesso em: 30 de maio de 2017.

VEIGA-NETO, Alfredo. Foucault \& a educação. Belo Horizonte: Autêntica, 2003.

WANDERER, Fernanda. Educação Matemática, processos de regulação e o Programa Escola Ativa. Revista de Educação Publica, Cuiabá, v. 26, n. 61, p. 201-221, jan./abr. 2017.

WANDERER, Fernanda; KNIJNIK, Gelsa. Processos avaliativos e/na educação matemática: um estudo sobre o Programa Escola Ativa. Educação, Porto Alegre, v. 37, n. 1, p. 92-100, jan./abr. 2014. https://doi.org/10.15448/19812582.2014.1.15880

Recebido em: 29/6/2017.

Aprovado em: 25/4/2019.

Publicado em: 8/11/2019.

Endereço para correspondência:

Fernanda Wanderer

Universidade Federal do Rio Grande do Sul

Faculdade de Educação - Programa de Pós-Graduação em Educação

Av. Paulo Gama, s/n, prédio 12201, 7o andar - Bairro Farroupilha

90046-900, Porto Alegre, RS, Brasil

\section{Autoras:}

FERnANDa WANDERER

Doutora em Educação, Universidade do Vale do Rio dos Sinos, São Leopoldo, RS, Brasil. Professora do Programa de Pós-Graduação em Educação, Universidade Federal do Rio Grande do Sul, Porto Alegre, RS, Brasil.

Orcid: https://orcid.org/0000-0002-8198-7104

E-mail: fernandawanderer@gmail.com

Daiane Martins Bocasanta

Doutora em Educação, Universidade do Vale do Rio dos Sinos, São Leopoldo, RS, Brasil. Professora do Colégio de Aplicação, Universidade Federal do Rio Grande do Sul, Porto Alegre, RS, Brasil.

Orcid: https://orcid.org/0000-0003-4430-4236

E-mail: daianebocasanta@gmail.com 